\title{
Active renin mass concentration to determine aldosterone-to-renin ratio in screening for primary aldosteronism
}

This article was published in the following Dove Press journal: International Journal of Nephrology and Renovascular Disease 27 July 2011

Number of times this article has been viewed

\author{
François Corbin' \\ Pierre Douville 2 \\ Marcel Lebel ${ }^{3}$ \\ 'Division of Biochemistry, l'Université \\ de Sherbrooke, Sherbrooke, Quebec, \\ Canada; ${ }^{2}$ Division of Biochemistry; \\ ${ }^{3}$ Division of Nephrology, L'Hôtel-Dieu \\ de Québec Hospital and l'Université \\ Laval, Quebec, Canada
}

Background: Active renin mass concentration (ARC) is independent of the endogenous level of angiotensinogen, and less variable and more reproducible than plasma renin activity. Reference values for the aldosterone-to-renin ratio (ARR) using ARC are still undefined. The objective of the present study was to determine the threshold of ARR using ARC measurement to screen for primary aldosteronism.

Methods: A total of 211 subjects were included in the study, comprising 78 healthy normotensive controls, 95 patients with essential hypertension, and 38 patients with confirmed primary aldosteronism (20 with surgery-confirmed aldosterone-producing adenoma and 18 with idiopathic adrenal hyperplasia). Blood samples were drawn from ambulatory patients and volunteers in the mid-morning without specific dietary restriction for measuring plasma aldosterone concentration, ARC, and serum potassium.

Results: Most normotensive controls and essential hypertension patients had ARR results below $100 \mathrm{pmol} / \mathrm{ng}$, a value which corresponded to 3.3 times the median of these two groups.

Conclusion: Patients with ARR values above this level should be considered for further investigation (confirmatory tests) or for repeat testing should ARR values be borderline. This study indicates that ARC can be used reliably in determining ARR for primary aldosteronism screening.

Keywords: primary aldosteronism, active renin mass concentration, aldosterone-to-renin ratio

\section{Introduction}

Primary aldosteronism, as initially described by Conn, ${ }^{1}$ is defined as an inappropriate and autonomous production of aldosterone by the adrenal glands. With improved screening approaches, such as the ratio of plasma aldosterone to renin levels (ARR), the average number of screened patients with primary aldosteronism has increased considerably. ${ }^{2-6}$ Plasma renin activity has been usually measured to define ARR. ${ }^{7-9}$ More recently, the use of active renin mass concentration (ARC), instead of the plasma renin activity assay, has gained broader acceptance. ${ }^{10}$ Indeed, ARC does not require ice cooling of the specimen, is independent of the endogenous level of angiotensinogen, is easier to standardize, and is more reproducible than plasma renin activity. In addition, studies have demonstrated a significant correlation between plasma renin activity and ARC measurements, ${ }^{11-14}$ although this correlation is weaker at low renin levels ${ }^{7}$ but improved under captopril stimulation. ${ }^{14}$ So far, only a few small studies have reported an ARR threshold using ARC measurements in screening for primary aldosteronism. ${ }^{15-18}$ The objective of the present study was to assess the value of ARC in determining ARR for primary aldosteronism screening.
Correspondence: Marcel Lebel L'Hôtel-Dieu de Québec Hospital, 9 McMahon Street, Quebec City, Quebec, GIR 3S3 Canada Tel +I 4185254444 extn I558 $\mathrm{Fax}+|4| 86915562$

Email marcel.lebel@crhdq.ulaval.ca 


\section{Methods and materials}

Blood samples for measuring plasma aldosterone concentration, ARC, and serum potassium were drawn according to the Endocrine Society Clinical Practice Guideline ${ }^{19}$ from ambulatory patients and volunteers in the midmorning at the outpatient clinic of the L'Hôtel-Dieu de Québec Hospital, a tertiary care center. Informed consent was obtained for all subjects, as required by the local ethics committee. Preliminary data for the current study has been reported previously. ${ }^{20}$ The control group was recruited from normotensive subjects (blood pressure below $140 / 90 \mathrm{mmHg}$ ) coming for routine blood samples. Patients with a history of hypertension, diabetes, or with cardiac, hepatic, or renal diseases were excluded. Hypertensive patients had the same blood samples drawn while being investigated for hypertension. Patients were diagnosed with essential hypertension when clinical and laboratory investigation excluded any secondary forms of hypertension. Among patients referred to us for sustained hypertension and hypokalemia, those with primary aldosteronism were included retrospectively in the analysis. The ARR using plasma renin activity or ARC was not measured prior to referral. Our initial investigation of these patients showed that they had low ARC, high plasma aldosterone concentrations, and increased ARR values. A definite diagnosis of primary aldosteronism was confirmed in all patients by demonstrating an inappropriate autonomous hypersecretion of aldosterone with captopril suppression and salt loading procedures as described previously. ${ }^{21}$ Subtyping investigations included computed tomography imaging with fine cuts $(2.5-3.0 \mathrm{~mm})$ and a postural stimulation test in all patients. ${ }^{22}$ Adrenal venous sampling (10 patients) and/or adrenal scintigraphy using 6 beta 131-iodomethyl19-norcholesterol after dexamethasone suppression (six patients) were performed in patients with conflicting results. Beta-blockers, clonidine, renin-angiotensin blockers, and thiazide diuretics were withdrawn progressively one week prior to the investigation. Spironolactone was discontinued six weeks prior to blood sampling. Postsynaptic $\alpha_{1}$ blockers and calcium channel blockers were maintained or added when necessary to control hypertension. No subject in any of the three groups was taking oral contraceptive pills.

Blood was collected in EDTA tubes for ARC and plasma aldosterone measurement, maintained at room temperature during delivery to the laboratory, and rapidly frozen at $-20^{\circ} \mathrm{C}$ after centrifugation. Plasma ARC was determined using a two-site immunometric assay (Renin III Generation, Cisbio Bioassays, Bedford, MA). Typical imprecision in the normal range for this assay shows coefficients of variation below $4 \%$ within-run and below $7.5 \%$ between-run. Reference values ranged from $7 \mathrm{ng} / \mathrm{L}$ to $25 \mathrm{ng} / \mathrm{L}$ in the recumbent position and from $12 \mathrm{ng} / \mathrm{L}$ to $43 \mathrm{ng} / \mathrm{L}$ after ambulation. Plasma aldosterone concentration was measured by radioimmunoassay according to the manufacturer's recommendations (DSL-8600 kit, Beckman Coulter, Fullerton, CA). Typical imprecision in the normal range for this assay shows coefficients of variation below $7 \%$ within-run and below $10 \%$ between-run. Reference values with patients in the recumbent position ranged from $90 \mathrm{pmol} / \mathrm{L}$ to $290 \mathrm{pmol} / \mathrm{L}$ and after normal ambulation from $290 \mathrm{pmol} / \mathrm{L}$ to $871 \mathrm{pmol} / \mathrm{L}$. Serum potassium was determined using an autoanalyzer system (Ilab 1800 or Beckman LX-20).

\section{Statistical analysis}

Results are expressed as mean \pm standard error of the mean. The unpaired Student's $t$-test was used to establish statistically significant differences between groups. Two approaches were tested to establish cutoff values and to assess sensitivity and specificity; the first one was based on laboratory reference values (upper limit for aldosterone and lower limit for renin) and the second one corresponded to the optimal discriminator from receiver-operating characteristic (ROC) curves (point closest to the upper left corner). For ARR, we used the 95th percentile for the controls and essential hypertension patients.

Table I Clinical and biochemical data

\begin{tabular}{llll}
\hline & Control subjects & Essential hypertension & Primary aldosteronism \\
\hline Number of subjects & 78 & 95 & 38 \\
Gender (F/M) & $35 / 43$ & $56 / 39$ & $13 / 25$ \\
Age (years, mean \pm SD) & $36 \pm 13$ & $5 I \pm 12$ & $53 \pm 11$ \\
Serum K (mmol/L) & $4.2 \pm 0.03(4.2)$ & $4.1 \pm 0.06(4.2)$ & $3.2 \pm 0.07^{\mathrm{a}}(3.2)$ \\
Plasma aldosterone (pmol/L) & $382 \pm 28(320)$ & $339 \pm 25(272)$ & $928 \pm 116^{\mathrm{a}}(664)$ \\
ARC (ng/L) & $11.3 \pm 0.8(10)$ & $19.7 \pm 2.9(9)$ & $2.3 \pm 0.2^{\mathrm{a}}(2)$ \\
Aldosterone/ARC ratio (pmol/ng) & $42.4 \pm 3.3(32)$ & $37.8 \pm 2.9(27)$ & $519 \pm 99^{\mathrm{a}}(278)$ \\
\hline
\end{tabular}

Notes: ${ }^{a} P<0.01$ versus control subjects and essential hypertension. Mean \pm standard error of the mean. The median value for serum $\mathrm{K}$, plasma aldosterone, ARC, and aldosterone/ARC ratio appears in brackets.

Abbreviation: ARC, active renin mass concentration. 
ROC curves were generated and their surfaces evaluated using the Mann-Whitney U test. For the ROC curves, controls and essential hypertension results were pooled to assess specificity. Statistical assessments of proportions were done using the $\chi^{2}$ test and Cohen's kappa test.

\section{Results}

A total of 211 subjects were included in the study, comprising 78 healthy normotensive controls, 95 patients with essential hypertension, and 38 patients with confirmed primary aldosteronism (20 had surgery-confirmed unique aldosteroneproducing adenoma and 18 were presumed to have idiopathic adrenal hyperplasia). Table 1 presents the patient characteristics and basal biochemical determinations. The mean age of control subjects was lower but not significantly different from the other two patient groups. Plasma aldosterone and ARR values were significantly higher $(P<0.01)$, and ARC and serum potassium values were significantly lower $(P<0.01)$ in primary aldosteronism patients. Mean ARR values were not significantly different in patients with unique adenoma and with idiopathic adrenal hyperplasia $(614 \pm 169 \mathrm{pmol} / \mathrm{ng}$ versus $414 \pm 91 \mathrm{pmol} / \mathrm{ng}, P>0.05)$. Figure 1 depicts individual values for plasma aldosterone, ARC, and ARR from the subjects in all three groups. ARR values (bottom graph) discriminate better between the primary aldosteronism patients, essential hypertension patients, and control subjects. Table 2 shows comparisons between the two approaches used to establish cutoff values in screening for primary aldosteronism (upper and lower limits of laboratory references or 95 th percentile values and ROC curve analysis). The results show that the ROC curve analysis has the best sensitivity and specificity in establishing cutoff values for ARR. Figure 2 shows ROC curves for plasma aldosterone concentration, ARC, and ARR. ARR values above $130 \mathrm{pmol} / \mathrm{ng}$ detected primary aldosteronism with a sensitivity and specificity of $100 \%$. Table 3 provides the area under the ROC curves \pm standard error of the mean and $95 \%$ confidence intervals.
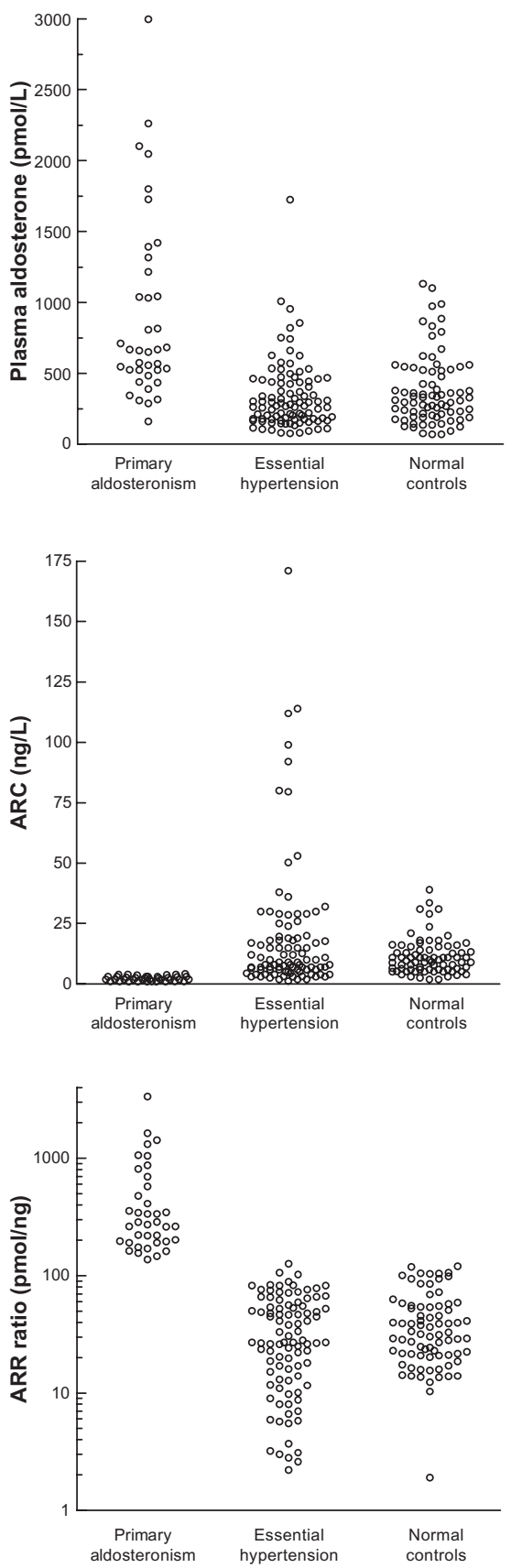

Figure I Individual values of plasma aldosterone, active renin mass concentration $(A R C)$ and aldosterone to renin ratio (ARR) in the three groups.

Table 2 Comparison of cutoff values derived from the upper limits of laboratory references or 95th percentile values and those from the receiver-operator characteristic curve

\begin{tabular}{lllllll}
\hline & & Cutoff values & Sens/spec. (\%) & Sens + spec-I (\%) & Accuracy (\%) $^{\mathbf{a}}$ & Kappa test \\
\hline \multirow{2}{*}{ Aldo } & ULR & $87 I \mathrm{pmol} / \mathrm{L}$ & $34 / 95$ & 29 & 84 & 0.36 \\
& ROC & $480 \mathrm{pmol} / \mathrm{L}$ & $79 / 77$ & 56 & 78 & 0.43 \\
\multirow{2}{*}{ ARC } & ULR & $7 \mathrm{ng} / \mathrm{dL}$ & $100 / 67$ & 67 & 78 & 0.43 \\
& ROC & $4.3 \mathrm{ng} / \mathrm{dL}$ & $100 / 85$ & 85 & 88 & 0.67 \\
\multirow{2}{*}{ ARR } & 95 th percentile & $101 \mathrm{pmol} / \mathrm{ng}$ & $100 / 95$ & 95 & 96 & 100 \\
& ROC & $130 \mathrm{pmol} / \mathrm{ng}$ & $100 / 100$ & 100 & 100 & 1.0 \\
\hline
\end{tabular}

Note: ${ }^{\mathrm{P}}<0.00 \mathrm{I}$ for all values. Control and essential hypertension populations were pooled to calculate specificity; the median for ARR is 30.6 with a 95 th percentile of I0I (3.3-fold the median).

Abbreviations: Aldo, plasma aldosterone concentration; ARC, active renin mass concentration; ARR, aldosterone-renin ratio; ROC, receiver-operator characteristic curve; ULR, upper limit of laboratory reference values; Sens/spec, sensitivity/specificity. 


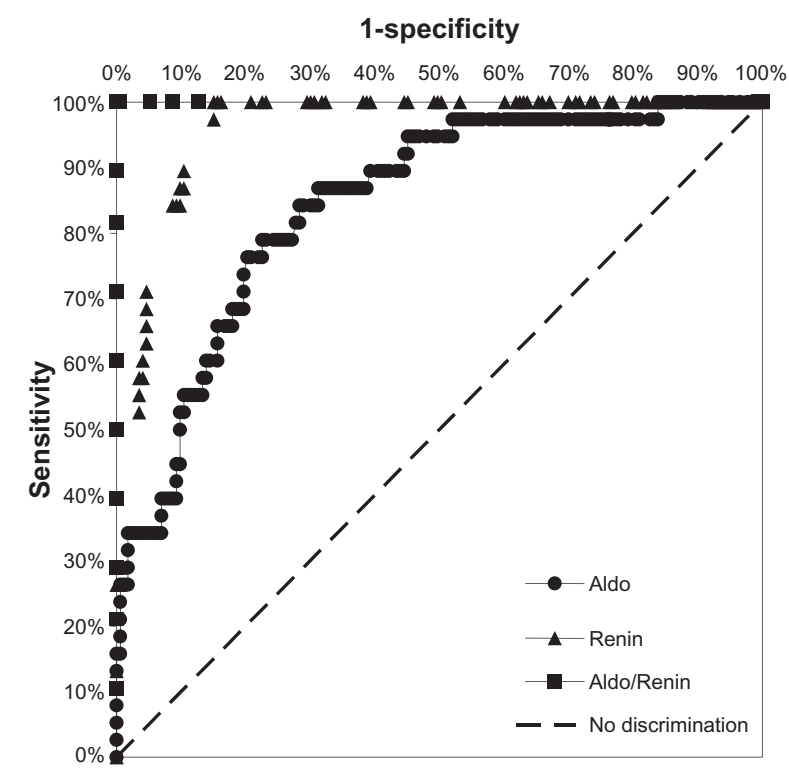

Figure 2 Analysis of receiver-operating characteristic curves. Circle, plasma aldosterone; triangle, active renin mass concentration; square, aldosterone to renin ratio.

There were significant correlations between serum potassium and ARR ( $\mathrm{r}=-333, P<0.001)$, and ARC $(\mathrm{r}=+0.304$, $P<0.001)$ and aldosterone $(\mathrm{r}=-0.274, P=0.007)$. All but three patients with essential hypertension had an ARR below $100 \mathrm{pmol} / \mathrm{ng}$ (106, 102, $126 \mathrm{pmol} / \mathrm{ng}$; range 2-126 pmol/ng). When repeated, the ratio value of $126 \mathrm{pmol} / \mathrm{ng}$ decreased to $56 \mathrm{pmol} / \mathrm{ng}$. All primary aldosteronism patients had ARR values above $130 \mathrm{pmol} / \mathrm{ng}$ (range 137-3349 pmol/ng). The mean ARR in normotensive subjects was $42.4 \pm 3.3 \mathrm{pmol} / \mathrm{ng}$ (range 2-118); five subjects were above $100 \mathrm{pmol} / \mathrm{ng}$ (104, 103, 104, 105, and $118 \mathrm{pmol} / \mathrm{ng}$ ). Table 4 shows suggested screening thresholds for ARR.

\section{Discussion}

In the present study, which included control subjects and patients with essential hypertension and primary aldosteronism, we used ARC to define ARR in screening for primary aldosteronism. Patients with essential hypertension and control subjects had similar mean ARR values (mostly

Table 3 Area under the receiver-operator characteristic curve \pm standard error of the mean and confidence intervals

\begin{tabular}{llll}
\hline & $\begin{array}{l}\text { Area under } \\
\text { curve }\end{array}$ & \pm SEM & $\begin{array}{l}\text { Confidence } \\
\text { interval (95\%) }\end{array}$ \\
\hline Aldo (pmol/L) & $0.86^{\mathrm{a}, \mathrm{b}}$ & 0.032 & $0.79-0.91$ \\
$\mathrm{ARC}(\mathrm{ng} / \mathrm{L})$ & $0.96^{\mathrm{c}}$ & 0.012 & $0.93-0.98$ \\
Aldo/ARC ratio & 1.0 & 0.002 & $0.95-1.00$ \\
(pmol/ng) & & & \\
\hline
\end{tabular}

Notes: ${ }^{a} P<0.01$ versus ARC; ${ }^{b} P<0.001$ versus aldo/ARC ratio; ${ }^{c} P<0.01$ versus aldo/ARC ratio.

Abbreviations: Aldo, plasma aldosterone concentration; ARC, active renin mass concentration; SEM, standard error of the mean.
Table 4 Suggested screening thresholds for aldosterone-to-renin ratio using active renin mass concentration ( $\mathrm{pmol} / \mathrm{ng}$ )

\begin{tabular}{ll}
\hline$\leq 100$ & Essential hypertension \\
$100-130$ & Gray zone (repeat) \\
$\geq 130$ & Primary aldosteronism \\
\hline
\end{tabular}

Note: ${ }^{\mathrm{a} C o m b i n e d ~ w i t h ~ p l a s m a ~ a l d o s t e r o n e ~ c o n c e n t r a t i o n ~}>416 \mathrm{pmol} / \mathrm{L}$.

below $100 \mathrm{pmol} / \mathrm{ng}$ ). ARR results above $130 \mathrm{pmol} / \mathrm{ng}$ indicated primary aldosteronism with a sensitivity and specificity of $100 \%$. ARR results that fall between $100 \mathrm{pmol} / \mathrm{ng}$ and $130 \mathrm{pmol} / \mathrm{ng}$ (gray zone) suggest a need for repeat testing.

So far, few laboratories have attempted to establish reference values for ARR by using ARC expressed as pmol/ng. In a group of 36 hypertensive patients (nine with adrenal adenoma), Ferrari et $\mathrm{al}^{12}$ reported that an $\mathrm{ARR} \geq 150 \mathrm{pmol} / \mathrm{ng}$ can indicate primary aldosteronism. Perschel et $\mathrm{al}^{16}$ measured ARR in 76 healthy normotensive volunteers and 28 primary aldosteronism patients. No patients with essential hypertension were included in that study. Their proposed cutoff value for ARR in normotensive volunteers versus primary aldosteronism patients was $118 \mathrm{pmol} / \mathrm{ng}$. The cutoff value adopted by Westerdahl et al ${ }^{18}$ to separate essential hypertension was $100 \mathrm{pmol} / \mathrm{ng}$.

To our knowledge, the current report is the largest study in this area, and included control subjects, essential hypertensives, and primary aldosteronism patients. We compared two approaches to establish the cutoff values for plasma aldosterone, ARC and ARR (Table 2). The ROC curve analysis was clearly the best performing test, and ARR showed the highest sensitivity and specificity in detecting primary aldosteronism.

The combination of an ARR cutoff value with a plasma aldosterone threshold ( $>416 \mathrm{pmol} / \mathrm{L}$ or $>15 \mathrm{ng} / \mathrm{dL}$ ) has been suggested by some investigators. ${ }^{8}$ This approach limits the number of false positive ARR, namely in patients with low renin essential hypertension, which represents around $25 \%$ of essential hypertension. However, to this end, it is important to use ambulatory plasma aldosterone values. Indeed, many patients with idiopathic adrenal hyperplasia exhibit normal early-morning plasma aldosterone values in the recumbent position, but their plasma aldosterone concentrations increase markedly with ambulation. ${ }^{22}$

As for many screening tests performed without rigorous conditions throughout daily routine blood samplings, we observed borderline ARR results overlapping the proposed cutoff values. For this reason, we introduced the notion of a "gray zone" to help clinicians sort out patients in whom ARR should be repeated. In such cases, more attention should be paid to sampling conditions, ie, dietary sodium intake and serum potassium concentration, with careful revision and 
adjustment of medication. In addition, it is important to point out that the thresholds reported in the current paper cannot be applied universally, and should be adapted to each laboratory depending on the assays utilized. To this end, the median values (see Table 1) can be used as comparison points; for instance, the proposed ARR threshold for control subjects and essential hypertension (100 pmol/ng) corresponds to 3.3 times the median value of these two groups.

The use of the ARR appears to be the preferred screening approach for distinguishing between patients with essential hypertension and those with primary aldosteronism. ${ }^{10,23}$ In past years, the ARR was based almost exclusively on plasma renin activity measurements. More recently, the utilization of ARC, instead of plasma renin activity, has gained acceptance. Indeed, studies have revealed a significant correlation between ARC and plasma renin activity assays. ${ }^{1-14}$ Moreover, the immunometric method to measure ARC offers many advantages over the plasma renin activity procedure. These advantages include this method being easier to standardize than the enzymatic assay, which can be altered by variation in the concentration of the endogenous angiotensinogen, having a better interlaboratory and intralaboratory coefficient of variation and reproducibility that allows comparisons between different laboratories, ${ }^{24}$ and angiotensin II being more closely correlated with immunoreactive renin than with plasma renin activity. ${ }^{25,26}$ Recent methods have improved the sensitivity of the assay, which can now be used to assess suppressed renin levels. ${ }^{27}$ Because of these advantages, $\mathrm{ARC}$ is progressively becoming the preferred method for measuring renin in humans. A recent study by $\mathrm{Wu}$ et $\mathrm{al}^{17}$ showed that ARC is as accurate as plasma renin activity when using the captopril suppression confirmatory test. In conclusion, this study indicates that ARC can be used reliably to determine ARR when screening for primary aldosteronism. Patients with essential hypertension usually have ARR values $\leq 100 \mathrm{pmol} / \mathrm{ng}$, while ARR in patients with primary aldosteronism is $\geq 130 \mathrm{pmol} / \mathrm{ng}$. Results that fall between 100 and $130 \mathrm{pmol} / \mathrm{ng}$ (gray zone) suggest a need for repeat testing.

\section{Disclosure}

The authors report no financial or other relationships that might lead to a conflict of interest in this work.

\section{References}

1. Conn J. Primary aldosteronism, a new clinical syndrome. J Lab Clin Med. 1955;45:3-17.

2. Young WF Jr. Primary aldosteronism: a common and curable form of hypertension. Cardiol Rev. 1999;7:207-214.
3. Gordon RD, Stowasser M, Tunny TJ, et al. High incidence of primary aldosteronism in 199 patients referred with hypertension. Clin Exp Pharmacol Physiol. 1994;21:315-318.

4. Fardella CE, Mosso L, Gomez-Sanchez C, et al. Primary hyperaldosteronism in essential hypertensives: prevalence, biochemical profile, and molecular biology. J Clin Endocrinol Metab. 2000;85:1863-1867.

5. Lim PO, Dow E, Brennan G, et al. High prevalence of primary aldosteronism in the Tayside hypertension clinic population. J Hum Hypertens. 2000;14:311-315.

6. Loh KC, Koay ES, Khaw MC, et al. Prevalence of primary aldosteronism among Asian hypertensive patients in Singapore. J Clin Endocrinol Metab. 2000;85:2854-2859.

7. Sealey JE, Gordon RD, Mantero F. Plasma renin and aldosterone measurements in low renin hypertensive states. Trends Endocrinol Metab. 2005;16:86-91.

8. Young WF. Primary aldosteronism: renaissance of a syndrome. Clin Endocrinol (Oxf). 2007;66:607-618.

9. Rossi GP, Seccia TM, Palumbo G, et al. Within-patient reproducibility of the aldosterone: renin ratio in primary aldosteronism. Hypertension. 2010;55:83-89.

10. Rossi GP, Seccia TM, Pessina AC. Clinical use of laboratory tests for the identification of secondary forms of arterial hypertension. Crit Rev Clin Lab Sci. 2007;44:1-85.

11. Unger N, Lopez Schmidt I, Pitt C, et al. Comparison of active renin concentration and plasma renin activity for the diagnosis of primary hyperaldosteronism in patients with an adrenal mass. Eur J Endocrinol. 2004;150:517-523.

12. Ferrari P, Shaw SG, Nicod J, et al. Active renin versus plasma renin activity to define aldosterone-to-renin ratio for primary aldosteronism. J Hypertens. 2004;22:377-381.

13. de Bruin RA, Bouhuizen A, Diederich S, et al. Validation of a new automated renin assay. Clin Chem. 2004;50:2111-2116.

14. Rossi GP, Barisa M, Belfiore A, et al. The aldosterone-renin ratio based on the plasma renin activity and direct renin assay for diagnosing aldosterone-producing adenoma. J Hypertens. 2010;28:1892-1899.

15. Trenkel S, Seifarth C, Schobel H, et al. Ratio of serum aldosterone to plasma renin concentration in essential hypertension and primary aldosteronism. Exp Clin Endocrinol Diabetes. 2002;110:80-85.

16. Perschel FH, Schemer R, Seiler L, et al. Rapid screening test for primary hyperaldosteronism: ratio of plasma aldosterone to renin concentration determined by fully automated chemiluminescence immunoassays. Clin Chem. 2004;50:1650-1655.

17. Wu VC, Kuo CC, Chang HW, et al. Diagnosis of primary aldosteronism: comparison of post-captopril active renin concentration and plasma renin activity. Clin Chim Acta. 2010;411:657-663.

18. Westerdahl C, Bergenfelz A, Isaksson A, et al. High frequency of primary hyperaldosteronism among hypertensive patients from a primary care area in Sweden. Scand J Prim Health Care. 2006;24:154-159.

19. Funder JW, Carey RM, Fardella C, et al. Case detection, diagnosis, and treatment of patients with primary aldosteronism: an Endocrine Society clinical practice guideline. J Clin Endocrinol Metab. 2008;93:3266-3281.

20. Racine MC, Douville P, Lebel M. Functional tests for primary aldosteronism: value of captopril suppression. Curr Hypertens Rep. 2002;4:245-249.

21. Agharazii M, Douville P, Grose JH, et al. Captopril suppression versus salt loading in confirming primary aldosteronism. Hypertension. 2001;37:1440-1443.

22. Plamondon I, Agharazii M, Douville P, et al. Morning plasma aldosterone predicts the subtype of primary aldosteronism independant of sodium intake. Clin Exp Hypertens. 2007;29:127-134.

23. Mulatero P, Stowasser M, Loh KC, et al. Increased diagnosis of primary aldosteronism, including surgically correctable forms, in centers from five continents. J Clin Endocrinol Metab. 2004;89: $1045-1050$.

24. Morganti A. A comparative study on inter and intralaboratory reproducibility of renin measurement with a conventional enzymatic method and a new chemiluminescent assay of immunoreactive renin. $J$ Hypertens. 2010;28:1307-1312. 
25. Menard J, Guyenne TT, Corvol P, et al. Direct immunometric assay of active renin in human plasma. J Hypertens. 1985;3(Suppl 3):S275-S278.

26. Juillerat L, Nussberger J, Menard J, et al. Determinants of angiotensin II generation during converting enzyme inhibition. Hypertension. 1990;16:564-572.
27. Deinum J, Derkx FH, Schalekamp MA. Improved immunoradiometric assay for plasma renin. Clin Chem. 1999;45:847-854.

\section{Publish your work in this journal}

The International Journal of Nephrology and Renovascular Disease is an international, peer-reviewed open-access journal focusing on the pathophysiology of the kidney and vascular supply. Epidemiology, screening, diagnosis, and treatment interventions are covered as well as basic science, biochemical and immunological studies. The journal welcomes original research, clinical studies, reviews \& evaluations, expert opinion and commentary, case reports and extended reports. The manuscript management system is completely online and includes a very quick and fair peerreview system, which is all easy to use. Visit http://www.dovepress.com/ testimonials.php to read real quotes from published authors.

Submit your manuscript here: http://www.dovepress.com/international-journal-of-nephrology-and-renovascular-disease-journal 